\title{
Comparison of nutrient composition in wild caught and cultured Cirrhinus molitorella (Valenciennes, 1844)
}

\author{
KE CUI ${ }^{1,2,4}$, FALIN ZHOU ${ }^{2,3}$, ZHENHUA MA $^{2,3}$ AND SHIGUI JIANG ${ }^{2,3}$ \\ ${ }^{1}$ College of Fisheries and Life Science, Shanghai Ocean University, Shanghai - 200 090, P. R. China \\ ${ }^{2}$ South China Sea Fisheries Research Institute, Chinese Academy of Fishery Sciences, Guangzhou - 510 300, P. R. China \\ ${ }^{3}$ Key Laboratory of South China Sea Fishery Resources Exploitation and Utilisation, Guangzhou - 510 300, P. R. China \\ ${ }^{4}$ College of Animal Science, South China Agricultural University, Guangzhou - 510 642, P. R. China \\ e-mail: zhenhua.ma@hotmail.com
}

\begin{abstract}
Proximate body composition and amino acid profile of flesh of wild Cirrhinus molitorella (Valenciennes, 1844) from a reservoir and a river was compared with that of $C$. molitorella cultured in an aquaculture pond. The results showed the fat content to be highest in C. molitorella caught from reservoir followed by samples from river and lowest in pond cultured fishes. Protein content exhibited the opposite trend. Flesh of C. molitorella from river had optimum protein quality while flesh of fishes from reservoir had the best taste. Flesh of $C$. molitorella was found to be nutritionally rich and well balanced and its high glutamic acid as well as lysine content made it a superior forage fish for Siniperca chuatsi. Overall, C. molitorella flesh had a more balanced nutritional composition, but lower nutritional value than that of seven other reference fish species.
\end{abstract}

Keywords: Amino acids, Cirrhinus molitorella, Crude fat, Crude protein

Cirrhinus molitorella (Valenciennes, 1844) (Family: Cyprinidae) is widely distributed in South China and South-east Asian countries along the Mekong River and is an important species contributing to the commercial fishery as well as in pond culture. In Guangdong and Guangxi provinces in China, C. molitorella is pond cultured for commercial purposes and also as a forage food for other fish. Wild stocks of C. molitorella in natural water bodies have declined (Nguyen et al., 2013) with a simultaneous increase in consumer demand and requirement for nutritional quality. Fish meat quality is affected by various factors including different cultivars, growing environments and natural food sources (Grigorakis, 2007). Fish flesh generally contains higher free amino acids than that of terrestrial animals (Haard, 1992). These amino acids are important contributors to taste (Solms, 1969) and plays important role in the quality of fish meat. The present study evaluated the composition of amino acids and other common nutritive components in the flesh of $C$. molitorella from three different water bodies in South China, aiming to provide basic data for the development of appropriate aquaculture models to improve flesh quality of $C$. molitorella.

The study was carried out in August 2012 in the laboratory of the South China Sea Fisheries Research Institute (SCSFI), Chinese Academy of Fishery Sciences, Guangzhou, China. Amino acid analysis was carried out by the Guangzhou Institute of Entomology, Guangdong, China. C. molitorella samples used were collected from a controlled reservoir (Songtao Reservoir in Hainan Province), a natural river (Xijiang River in Shaoqing City, Guangdong Province) and an aquaculture pond in Foshan City, Guangdong Province, respectively. Five healthy fish were sampled from each site, euthanised by an overdose $\left(60 \mathrm{mg} \mathrm{l}^{-1}\right)$ of AQYI-S ${ }^{\circledR}$ and transported to the laboratory with ice packs. After measurement of body length and weight (using an electronic balance OHAUS, USA), (Table 1) flesh from the fish were removed, along with the fishbone, using a boning knife. Flesh was then chopped to $<1 \mathrm{~cm}$ using a scalpel and stored at $-75^{\circ} \mathrm{C}$ until analysis. Moisture content in flesh was determined as:

Percentage moisture content of flesh $=\frac{\mathrm{W} 1-\mathrm{W} 2}{\mathrm{~W} 1-\mathrm{W} 0} \times 100$

where $\mathrm{W} 1=$ weight of the pre-dried pan and fresh fish meat before drying at $120^{\circ} \mathrm{C} ; \mathrm{W} 2=$ weight of the pre-dried pan and fish meat after drying at $120^{\circ} \mathrm{C}$; W0 $=$ constant weight of the pre-dried pan.

Crude ash was determined as per the method described in GB5009.4-2010 (2010).

Table 1. Body length and weight of Cirrhinus molitorella from three sampling sites

\begin{tabular}{llll}
\hline Parameters & Songtao Reservoir & Xijiang River & Aquaculture pond \\
\hline Length $(\mathrm{cm})$ & $26.18 \pm 1.29$ & $26.98 \pm 2.64$ & $27.9 \pm 1.01$ \\
Weight $(\mathrm{g})$ & $507.2 \pm 70.22$ & $495.8 \pm 51.01$ & $510.2 \pm 28.85$ \\
\hline
\end{tabular}


Percentage of crude ash $=\frac{\mathrm{W} 1-\mathrm{W} 2}{\mathrm{~W} 1-\mathrm{W} 0} \times 100$

where, W1=weight of pre-burned crucible and ash (g); $\mathrm{W} 2=$ weight of pre-burned crucible $(\mathrm{g})$; $\mathrm{W} 0=$ =weight of the pre-burned crucible and dried sample before burning (g).

Crude fat content was determined as described in GB5009.6-2003 (2003).

Percentage crude fat $=\frac{\mathrm{W} 1-\mathrm{W} 2}{\mathrm{~W} 0} \times 100$

where, W1=weight of aluminum cup and residue (g); $\mathrm{W} 2=$ weight of aluminum cup $(\mathrm{g}) ; \mathrm{W} 0=$ weight of fresh fish meat $(\mathrm{g})$.

Crude protein content was calculated as per GB5009.5-2010 (2010) from the nitrogen content using the following formula:

Percentage of crude protein $=\frac{\left(\mathrm{V}_{2}-\mathrm{V}_{1}\right) \times \mathrm{C} \times 0.0140 \times 6.25}{\mathrm{~m} \times \frac{\mathrm{V}^{\prime}}{\mathrm{V}}} \times 100 \%$

where, $v_{1}=$ volume of standard acid solution used in titration of the fish meat sample $(\mathrm{ml}) ; \mathrm{v}_{2}=$ volume of standard acid solution used in the titration of the control $(\mathrm{ml}) ; \mathrm{C}=$ concentration of standard $\mathrm{HCl}$ solution $\left(\mathrm{mol} \mathrm{l}^{-1}\right) ; \mathrm{m}=$ weight of fresh fish sample $(\mathrm{g}) ; \mathrm{v}=$ total volume of the sample digest $(\mathrm{ml}) ; \mathrm{v}^{\prime}=$ volume of the sample digest used for evaporation $(\mathrm{ml}) ; 0.014=$ nitrogen milligram equivalent $(\mathrm{mEq})(\mathrm{g})$ of $1 \mathrm{ml}$ standard $\mathrm{HCl}\left(1 \mathrm{~mol} \mathrm{l}^{-1}\right)$ solution; $6.25=$ average conversion coefficient from nitrogen to protein.

Amino acid content was determined by hydrochloric acid hydrolysis, as described in GB/T5009.124-2003. (2003). The sample was dehydrated by drying, defatted by Soxhlet extraction, mashed, added $6 \mathrm{~mol} \mathrm{l}^{-1}$ analytical $\mathrm{HCl}$, ultrasonicated, vacuum sealed and hydrolysed at $110^{\circ} \mathrm{C}$ for $24 \mathrm{~h}$. The hydrolysate was then evaporated in a pan to remove the solvent. The residue was diluted with water to a constant volume and sent to the Institute of Entomology in Guangzhou for analysis of amino acids (excluding tryptophan) in a L-8800 automatic amino acid analyser (Hitachi Ltd., Japan) in triplicates.

Nutritive value of $C$. molitorella flesh were evaluated in comparison with the ratios and patterns of amino acids recommended by the Food and Agricultural Organiszation (FAO, 1973) and the ratios and patterns of amino acids in whole egg protein (Cai et al., 1980). Amino acids scores
(AAS), chemical scores (CS) and the essential amino acid index (EAAI) were calculated following Tan et al. (2004):

$\mathrm{AAS}=$ content of single amino acid in the sample $\left(\mathrm{mg} \mathrm{gN}^{-1}\right) /$ content of the same amino acid in $\mathrm{FAO} / \mathrm{WHO}$ criteria $\left(\mathrm{mg} \mathrm{gN}^{-1}\right)$;

$\mathrm{CS}=$ content of single amino acid in the sample $\left(\mathrm{mg} \mathrm{gN}^{-1}\right) /$ content of the same amino acid in whole egg protein $\left(\mathrm{mg} \mathrm{gN}^{-1}\right)$

$\mathrm{EAAI}=\sqrt[n]{100 \mathrm{a} / \mathrm{A} \times 100 \mathrm{~b} / \mathrm{B} \times \ldots .100 \mathrm{j}}$

where, $\mathrm{n}=$ number of amino acids used in the evaluation; $a, b, c, \ldots j=$ contents of each amino acid in the fish meat proteins; $\mathrm{A}, \mathrm{B}, \mathrm{C}, \ldots \mathrm{J}=$ contents of each amino acid in the whole egg protein.

The average contents of moisture, crude ash, crude protein and crude fat in the $C$. molitorella meat from the three sampling sites are given in Table 2. Moisture content was the highest, followed by protein, fat and ash. Among the three sampling sites, flesh moisture and crude protein content in C. molitorella from Songtao Reservoir was highest, followed by that from Xijiang River $(p>0.05)$ and aquaculture pond $(p<0.05)$. Crude fat content was highest in fish flesh collected from aquaculture pond, followed by that from Xijiang River $(p>0.05)$ and Songtao Reservoir $(p<0.05)$. Crude ash content was highest in fish from Xijiang River, followed by aquaculture pond ( $>0.05)$ and Songtao Reservoir $(\mathrm{p}<0.05)$. Overall, the difference in basic nutritional composition was most significant between Songtao Reservoir and aquaculture pond.

The basic nutritional composition of $C$. molitorella (based on data from the present study) and of seven other cultured freshwater fish species are listed in Table 3 (Liu et al., 2008; Yan et al., 1995). The average protein content of $C$. molitorella was lower than that of Mylopharyngodon piceus, equal to that of Siniperca chuatsi and higher than that of the other five species. Fat content of $C$. molitorella was equal to that of Hypophthalmichthys molitrix and higher than that of the other five species. Variations in the nutritional composition between species could be attributed to the difference in their living environment.

Table 2. Basic nutritional composition of $C$. molitorella flesh from three sampling sites

\begin{tabular}{|c|c|c|c|c|c|c|}
\hline \multirow{2}{*}{ Components } & \multicolumn{3}{|c|}{ Percentage ( $\%$ of wet weight) } & \multicolumn{3}{|c|}{$\mathrm{p}$ value } \\
\hline & Songtao Reservoir & Xijiang River & Aquaculture pond & $\mathrm{p}_{12}$ & $\mathrm{p}_{13}$ & $\mathrm{p}_{23}$ \\
\hline Moisture & $75.38 \pm 0.83 a$ & $74.92 \pm 0.92 \mathrm{a}$ & $72.96 \pm 0.44 b$ & 0.683 & 0.002 & 0.0086 \\
\hline Crude ash & $0.96 \pm 0.14 b$ & $1.16 \pm 0.07 \mathrm{a}$ & $1.08 \pm 0.06 \mathrm{ab}$ & 0.0267 & 0.1963 & 0.4904 \\
\hline Crude fat & $3.70 \pm 3.12 b$ & $5.60 \pm 1.74 b$ & $9.72 \pm 1.59 \mathrm{a}$ & 0.4796 & 0.007 & 0.0588 \\
\hline Crude protein & $18.59 \pm 0.36 \mathrm{a}$ & $17.67 \pm 0.39 b$ & $17.22 \pm 0.73 b$ & 0.0673 & 0.0076 & 0.4606 \\
\hline
\end{tabular}


Table 3. Basic proximate composition of C. molitorella and seven other cultured freshwater fish species

\begin{tabular}{|c|c|c|c|c|}
\hline & Moisture (\%) & Crude ash $(\%)$ & Crude protein $(\%)$ & Crude fat $(\%)$ \\
\hline Mylopharyngodon piceus ${ }^{*}$ & 79.63 & 1.23 & 18.11 & 1.02 \\
\hline Ctenopharyngodon idella* & 81.59 & 1.22 & 15.94 & 0.62 \\
\hline Hypophthalmichthys molitrix* & 76.48 & 1.17 & 15.8 & 5.54 \\
\hline Aristichthys nobilis* & 78.89 & 1.16 & 16.26 & 3.04 \\
\hline Cyprinus carpio* $^{*}$ & 79.58 & 1.18 & 16.52 & 2.03 \\
\hline Carassius auratus ${ }^{*}$ & 80.28 & 1.64 & 15.74 & 1.58 \\
\hline Siniperca chuatsi ${ }^{* *}$ & 79.76 & 1.06 & 17.56 & 1.504 \\
\hline Cirrhinus molitorella ${ }^{* * * *}$ & 75.2 & 1.05 & 17.83 & 6.34 \\
\hline
\end{tabular}

"Data from Liu (1990); ** Data from Yan et al. (1995); ${ }^{* * *}$ Present study (average from Table 2)

Eighteen amino acids in the fish flesh samples including seven essential amino acids (EAA) (threonine, valine, methionine, isoleucine, leucine, phenylalanine and lysine), two half-essential amino acids (HEAA) (histidine and arginine), eight nonessential amino acids (NEAA) (aspartic acid, serine, glutamic acid, proline, glycine, alanine, cystine and tyrosine) and one non-protein amino acid (taurine) were detected by acid hydrolysis (Table 4). Among them, aspartic acid, glutamic acid, glycine and alanine are flavour amino acids (FAA). In C. molitorella, the content of glutamic acid was highest, followed by aspartic acid, lysine and leucine, with cystine being the lowest among all amino acids. Glutamine and asparagine are converted to glutamate and aspartate due to acid hydrolysis and cystine is generally destroyed due to acid hydrolysis. In addition, the contents of histidine, methionine and proline were relatively low. The content of EAA accounted for $40 \%$ of total amino acids and the ratio of EAA to NEAA was higher than $60 \%$ ( Li et al., 1988). C. molitorella samples from Songtao Reservoir had significantly higher threonine, glutamic acid, NEAA and FAA content $(p<0.05)$ and significantly lower methionine and valine content than that from Xijiang River and the aquaculture pond $(\mathrm{p}<0.05)$. In addition, C. molitorella from Songtao Reservoir had significantly lower phenylalanine and lysine content than that from the aquaculture pond $(\mathrm{p}<0.05)$. C. molitorella from Xijiang River had significantly lower cystine content than

Table 4. Amino acid composition in C. molitorella from three sampling areas

\begin{tabular}{|c|c|c|c|c|c|c|}
\hline \multirow{2}{*}{ Amino acids } & \multicolumn{3}{|c|}{ Percentage $(\%$ of $\mathrm{FW})$} & \multicolumn{3}{|c|}{$\mathrm{p}$ value } \\
\hline & Songtao Reservoir & Xijiang River & Aquaculture pond & $\mathrm{p}_{12}$ & $\mathrm{p}_{13}$ & $\mathrm{p}_{23}$ \\
\hline Aspartate & $1.707 \pm 0.04 \mathrm{a}$ & $1.674 \pm 0.03 \mathrm{a}$ & $1.646 \pm 0.04 \mathrm{a}$ & 0.4238 & 0.0823 & 0.5413 \\
\hline Threonine & $0.682 \pm 0.11 \mathrm{a}$ & $0.661 \pm 0.01 \mathrm{~b}$ & $0.632 \pm 0.02 \mathrm{ab}$ & 0.1974 & 0.0025 & 0.0666 \\
\hline Serine & $0.567 \pm 0.03 \mathrm{a}$ & $0.529 \pm 0.01 \mathrm{c}$ & $0.477 \pm 0.03 b$ & 0.0895 & 0.0004 & 0.0202 \\
\hline Glutamic acid & $2.572 \pm 0.04 \mathrm{a}$ & $2.479 \pm 0.05 b$ & $2.444 \pm 0.05 b$ & 0.0551 & 0.0093 & 0.5936 \\
\hline Proline & $0.530 \pm 0.03 \mathrm{a}$ & $0.492 \pm 0.00 \mathrm{ab}$ & $0.507 \pm 0.03 \mathrm{~b}$ & 0.1064 & 0.401 & 0.6576 \\
\hline Glycine & $0.744 \pm 0.03 \mathrm{a}$ & $0.694 \pm 0.00 \mathrm{ab}$ & $0.697 \pm 0.04 b$ & 0.1003 & 0.127 & 0.9889 \\
\hline Alanine & $0.981 \pm 0.03 \mathrm{a}$ & $0.959 \pm 0.01 \mathrm{a}$ & $0.952 \pm 0.04 \mathrm{a}$ & 0.5334 & 0.3319 & 0.9211 \\
\hline Cystine & $0.078 \pm 0.00 \mathrm{a}$ & $0.074 \pm 0.00 \mathrm{a}$ & $0.077 \pm 0.00 \mathrm{~b}$ & 0.0092 & 0.7467 & 0.0345 \\
\hline Valine & $0.770 \pm 0.01 \mathrm{c}$ & $0.843 \pm 0.01 \mathrm{a}$ & $0.860 \pm 0.02 b$ & $<.0001$ & $<.0001$ & 0.2586 \\
\hline Methionine & $0.447 \pm 0.00 \mathrm{~b}$ & $0.530 \pm 0.00 \mathrm{a}$ & $0.537 \pm 0.00 \mathrm{a}$ & $<.0001$ & $<.0001$ & 0.3166 \\
\hline Isoleucine & $0.726 \pm 0.02 b$ & $0.762 \pm 0.01 \mathrm{a}$ & $0.756 \pm 0.02 \mathrm{a}$ & 0.0235 & 0.0613 & 0.8532 \\
\hline Leucine & $1.275 \pm 0.03 \mathrm{a}$ & $1.306 \pm 0.02 \mathrm{a}$ & $1.296 \pm 0.03 \mathrm{a}$ & 0.3071 & 0.5388 & 0.8937 \\
\hline Tyrosine & $0.536 \pm 0.02 \mathrm{a}$ & $0.514 \pm 0.00 \mathrm{a}$ & $0.520 \pm 0.02 \mathrm{a}$ & 0.1353 & 0.3495 & 0.8036 \\
\hline Phenylalanine & $0.686 \pm 0.03 b$ & $0.715 \pm 0.00 \mathrm{a}$ & $0.753 \pm 0.03 b$ & 0.2851 & 0.0081 & 0.133 \\
\hline Lysine & $1.453 \pm 0.03 b$ & $1.489 \pm 0.02 \mathrm{a}$ & $1.536 \pm 0.05 b$ & 0.3472 & 0.016 & 0.1941 \\
\hline Histidine & $0.428 \pm 0.06 \mathrm{a}$ & $0.436 \pm 0.01 \mathrm{a}$ & $0.428 \pm 0.02 \mathrm{a}$ & 0.9519 & 0.9999 & 0.9473 \\
\hline Arginine & $0.964 \pm 0.06 \mathrm{a}$ & $0.891 \pm 0.01 \mathrm{a}$ & $0.895 \pm 0.03 \mathrm{a}$ & 0.7576 & 0.8322 & 0.9898 \\
\hline Taurine & $0.11 \pm 0.00 \mathrm{~b}$ & $0.11 \pm 0.00 \mathrm{~b}$ & $0.125 \pm 0.00 \mathrm{a}$ & 1 & 0.0064 & 0.0064 \\
\hline$W_{\mathrm{TAA}}$ & $15.347 \pm 0.31 \mathrm{a}$ & $15.449 \pm 0.25 \mathrm{a}$ & $15.408 \pm 0.46 \mathrm{a}$ & 0.9124 & 0.9675 & 0.9852 \\
\hline$W_{\mathrm{EAA}}$ & $6.038 \pm 0.20 \mathrm{~b}$ & $6.305 \pm 0.09 \mathrm{a}$ & $6.370 \pm 0.15 \mathrm{a}$ & 0.1602 & 0.0525 & 0.7892 \\
\hline$W_{\text {HEAA }}$ & $1.392 \pm 0.69 \mathrm{a}$ & $1.327 \pm 0.02 \mathrm{a}$ & $1.322 \pm 0.05 \mathrm{a}$ & 0.9744 & 0.8745 & 0.9582 \\
\hline$W_{\text {NEAA }}$ & $7.714 \pm 0.14 \mathrm{a}$ & $7.415 \pm 0.12 b$ & $7.320 \pm 0.24 b$ & 0.0763 & 0.0197 & 0.7296 \\
\hline$W_{\mathrm{FAA}}$ & $6.004 \pm 0.09 \mathrm{a}$ & $5.807 \pm 0.17 \mathrm{a}$ & $5.739 \pm 0.12 \mathrm{a}$ & 0.1231 & 0.0347 & 0.7487 \\
\hline$W_{\mathrm{EAA}} / W_{\mathrm{TAA}}(\%)$ & 39.34 & 40.81 & 41.34 & & & \\
\hline$W_{\text {EAA }} / W_{\text {NEAA }}(\%)$ & 78.27 & 85.03 & 87.02 & & & \\
\hline
\end{tabular}

$W_{\text {EAA }}$ - weight of EAA; $W_{\text {NEAA }}$ - weight of NEAA; $W_{\text {TAA }}$ - weight of TAA 
that from Songtao Reservoir and the aquaculture pond $(p<0.05)$ and significantly higher isoleucine content than that from Songtao Reservoir $(\mathrm{p}<0.05)$. C. molitorella from the aquaculture pond had significantly higher serine content and significantly lower taurine content than that from Songtao Reservoir and Xijiang River $(\mathrm{p}<0.05)$.

A comparison of amino acid content of C. molitorella (present study) and S. chuatsi flesh (Yan et al., 1995) is presented in Table 5. In $S$. chuatsi, glutamic acid accounted for the largest percentage of amino acids, followed by aspartate, lysine and leucine. Percentage of cystine was the lowest, with the percentages of histidine, methionine and tyrosine also relatively low. Percentages of each amino acid in $S$. chuatsi were very close to those in $C$. molitorella, with the maximum difference not higher than $0.7 \%$. Percentage of total EAA in C. molitorella was higher than that in $S$. chuatsi. Except for arginine and threonine, which were $\sim 0.3 \%$ lower than that in $S$. chuatsi, the percentages of all other EAA in C. molitorella were higher than those in S. chuatsi.

The data in Table 4 were converted to milligram amino acids per gram nitrogen $\left(\mathrm{mg} \mathrm{g} \mathrm{N}^{-1}\right)$ in dehydrated flesh $[62.5 \% \times$ amino acids content in fresh flesh/ (1- average moisture content of flesh)]. We then referred to the ratios and patterns of amino acids recommended by $\mathrm{FAO} / \mathrm{WHO}$ and to the ratios and patterns of amino acids in whole egg protein to determine AAS, CS and EAAI of $C$. molitorella flesh from the three sampling sites. Excluding tryptophan, the assessment score of lysine was higher than that of the other EAAs, while methionine and cystine scores were relatively low in C. molitorella from all sampling sites (Table 6). In general, there were no significant differences in single amino acid scores among the $C$. molitorella samples from the three sites (tryptophan not included). Samples of $C$. molitorella from Xijiang River had the highest EAAI value, followed by those from Songtao Reservoir and the aquaculture pond (Table 6).

Amino acid content ratios of C. molitorella and seven other cultured freshwater fish (Liu, 1990; Yan et al., 1995) are shown in Table 7. Total amino acid (TAA) and EAA contents in C. molitorella were only lower than those in S. chuatsi. The average $W_{\mathrm{EAA}} / W_{\mathrm{TAA}}$ value and average $W_{\text {EAA }} / W_{\text {NEAA }}$ value of $C$. molitorella were slightly higher and significantly higher, respectively, than that of the other seven fish species. The EAAI value of $C$. molitorella was significantly lower than that of the other seven fish species.

The difference in basic nutritive components of fish flesh among the three sampling sites was mainly in dry matter between samples from Songtao Reservoir and the aquaculture pond. Songtao Reservoir had higher water temperature ( $\mathrm{Ge}$ and $\mathrm{Yu}, 2009)$ than Xijiang River or the aquaculture pond, while the aquaculture pond had superior nutritional conditions than those of Songtao Reservoir or Xijiang River. Fish in environments with higher accumulated temperature have higher metabolic rates, which makes it difficult to obtain sufficient energy for growth and development. In addition, naturally growing fish have to prey for food, which also results

Table 5. Amino acid composition in C. molitorella and Siniperca chuatsi

\begin{tabular}{|c|c|c|c|c|c|}
\hline \multirow[t]{2}{*}{ Amino acid } & & \multicolumn{2}{|c|}{ Percentage ( $\%$ of wet weight) } & \multicolumn{2}{|c|}{ Percentage ( $\%$ of TAA) } \\
\hline & & S. chuatsi* & C. molitorella & S. chuatsi ${ }^{*}$ & C. molitorella \\
\hline \multirow[t]{8}{*}{ NEAA } & Aspartate & 1.85 & 1.68 & 10.92 & 11.16 \\
\hline & Tyrosine & 0.52 & 0.52 & 3.07 & 3.45 \\
\hline & Serine & 0.68 & 0.52 & 4.01 & 3.45 \\
\hline & Glutamic acid & 2.93 & 2.5 & 17.3 & 16.6 \\
\hline & Glycine & 0.81 & 0.71 & 4.78 & 4.71 \\
\hline & Proline & 0.69 & 0.51 & 4.07 & 3.39 \\
\hline & Alanine & 1.09 & 0.96 & 6.43 & 6.37 \\
\hline & Cystine & 0.17 & 0.08 & 1 & 0.53 \\
\hline \multirow[t]{7}{*}{ EAA } & Valine & 0.88 & 0.82 & 5.19 & 5.44 \\
\hline & Methionine & 0.51 & 0.5 & 3.01 & 3.32 \\
\hline & Isoleucine & 0.84 & 0.75 & 4.96 & 4.98 \\
\hline & Leucine & 1.44 & 1.29 & 8.5 & 8.57 \\
\hline & Phenylalanine & 0.73 & 0.72 & 4.31 & 4.78 \\
\hline & Lysine & 1.56 & 1.49 & 9.21 & 9.89 \\
\hline & Threonine & 0.8 & 0.66 & 4.72 & 4.38 \\
\hline \multirow[t]{4}{*}{ HEAA } & Histidine & 0.36 & 0.43 & 2.13 & 2.86 \\
\hline & Arginine & 1.08 & 0.92 & 6.38 & 6.11 \\
\hline & $W_{\mathrm{EAA}}$ & 8.2 & 7.58 & 48.41 & 50.33 \\
\hline & $W_{\mathrm{TAA}}$ & 16.94 & 15.06 & & \\
\hline
\end{tabular}

"Data from Yan et al. (1995), $W_{\mathrm{NEAA}}$ - weight of EAA; $W_{\mathrm{TAA}}$ - weight of TAA 
Table 6. EAA composition in C. molitorella from three sampling sites

\begin{tabular}{|c|c|c|c|c|c|c|c|c|c|}
\hline \multirow{2}{*}{ Indices } & \multirow{2}{*}{ Amino acids } & \multicolumn{5}{|c|}{$\begin{array}{l}\text { Milligram amino acids per gram nitrogen in dehydrated flesh } \\
\text { (mg amino acids / } \mathrm{g} \mathrm{N} \text { ) }\end{array}$} & \multicolumn{3}{|c|}{ Scores } \\
\hline & & $\begin{array}{l}\text { FAO } \\
\text { criteria }\end{array}$ & $\begin{array}{l}\text { Whole egg } \\
\text { protein criteria }\end{array}$ & $\begin{array}{l}\text { Songtao } \\
\text { Reservoir }\end{array}$ & $\begin{array}{l}\text { Xijiang } \\
\text { River }\end{array}$ & $\begin{array}{l}\text { Aquaculture } \\
\text { pond }\end{array}$ & $\begin{array}{l}\text { Songtao } \\
\text { Reservoir }\end{array}$ & $\begin{array}{l}\text { Xijiang } \\
\text { River }\end{array}$ & $\begin{array}{l}\text { Aquaculture } \\
\text { pond }\end{array}$ \\
\hline \multirow[t]{8}{*}{ AAS } & Isoleucine & 2.5 & & 1.843 & 1.899 & 1.747 & 0.737 & 0.76 & 0.7 \\
\hline & Leucine & 4.4 & & 3.237 & 3.255 & 3 & 0.736 & 0.74 & 0.682 \\
\hline & Lysine & 3.4 & & 3.689 & 3.711 & 3.55 & 1.085 & 1.092 & 1.044 \\
\hline & Threonine & 2.5 & & 1.707 & 1.647 & 1.461 & 0.683 & 0.659 & 0.584 \\
\hline & Valine & 3.1 & & 1.955 & 2.1 & 1.987 & 0.631 & 0.677 & 0.641 \\
\hline & Tryptophan & 0.6 & & 1 & I & / & / & 1 & 1 \\
\hline & Methionine + Cystine & 2.2 & & 1.333 & 1.504 & 1.419 & 0.606 & 0.684 & 0.645 \\
\hline & Phenylalanine + Tyrosine & 3.8 & & 3.102 & 3.063 & 2.94 & 0.816 & 0.806 & 0.774 \\
\hline \multirow[t]{8}{*}{ CS } & Isoleucine & & 3.31 & 1.843 & 1.899 & 1.747 & 0.557 & 0.574 & 0.528 \\
\hline & Leucine & & 5.34 & 3.237 & 3.255 & 3 & 0.606 & 0.61 & 0.562 \\
\hline & Lysine & & 4.41 & 3.689 & 3.711 & 3.55 & 0.837 & 0.841 & 0.805 \\
\hline & Threonine & & 2.92 & 1.707 & 1.647 & 1.461 & 0.585 & 0.564 & 0.5 \\
\hline & Valine & & 4.1 & 1.955 & 2.1 & 1.987 & 0.477 & 0.512 & 0.485 \\
\hline & Tryptophan & & 0.99 & / & I & I & / & I & / \\
\hline & Methionine + Cystine & & 3.86 & 1.333 & 1.504 & 1.419 & 0.345 & 0.39 & 0.368 \\
\hline & Phenylalanine + Tyrosine & & 5.65 & 3.102 & 3.063 & 2.94 & 0.55 & 0.542 & 0.52 \\
\hline EAAI & & & & & & & 54.86 & 56.32 & 52.56 \\
\hline
\end{tabular}

Table 7. Amino acid content ratio in C. molitorella and seven other cultured freshwater fish species

\begin{tabular}{llllll}
\hline Species & $\mathrm{W}_{\mathrm{TAA}}$ & $\mathrm{W}_{\mathrm{EAA}}$ & $\mathrm{W}_{\mathrm{EAA}} / \mathrm{W}_{\mathrm{TAA}}$ & $\mathrm{W}_{\mathrm{EAA}} / \mathrm{W}_{\mathrm{NEAA}}$ & EAAI \\
\hline M. piceus* & 14.04 & 5.68 & 40.46 & 0.68 & 67.62 \\
C. idella $^{*}$ & 12.37 & 4.97 & 40.18 & 0.67 & 62.71 \\
H. molitrix* & 14.79 & 5.64 & 38.13 & 0.62 & 60.73 \\
A. nobilis & 14.98 & 5.96 & 39.79 & 0.66 & 68.44 \\
C. carpio* & 13.94 & 5.58 & 40.03 & 0.67 & 68.96 \\
C. auratus* & 15.1 & 6.04 & 40 & 0.67 & 71.25 \\
S. chuatsi** & 16.94 & 6.76 & 39.91 & 0.66 & 81.02 \\
C. molitorella & 15.4 & 6.23 & 40.5 & 0.83 & 54.58 \\
\hline
\end{tabular}

" Data from Liu (1990); "** Data from Yan et al. (1995)

in high metabolic rates and significant activity costs. Fat content of fish in Songtao Reservoir was lowest, followed by that in Xijiang River, with highest fat content in fish from aquaculture pond. Due to the long-term high metabolic costs, fish from Songtao Reservoir had lower fat content, but higher protein content than that of fish from the aquaculture pond.

Protein and fat are chief components and important indicators of fish flesh quality. Generally, high protein and fat content indicate high quality fish meat (Fu et al., 2011). Compared with the seven other cultured freshwater fish, C. molitorella had higher average protein and fat content than all other species, except for $M$. piceus. Therefore the flesh quality of $C$. molitorella was found to be lower than that of M. piceus, while higher than that of $C$. idella, H. molitrix, A. nobilis, C. carpio, C. auratus and S. chuatsi.

Of the 18 amino acids in C. molitorella, glutamic acid content was the highest. Glutamic acid, which is one of the flavour amino acids (FAA) also plays an important role in the biochemical metabolism of brain tissue and is involved in the synthesis of several physiologically active substances (Zhang et al., 1988). Lysine content was also high in C. molitorella. As lysine, methionine and tryptophan are generally lacking in cereal, lysine is often classified as the main limiting amino acid in the human body (Chen, 1984). Cystine content was the lowest as well as a limiting amino acid in C. molitorella. In addition, C. molitorella flesh also contained taurine, a special amino acid that is functional in anti-oxidation and in improving immunity (Zhou et al., 2009) and thus is important for human and animal health.

As to the difference in amino acid categories, the EAA content in $C$. molitorella from the aquaculture pond was higher than that from Songtao Reservoir, while the NEAA content from Songtao Reservoir was higher than that from the aquaculture pond. The $W_{\mathrm{EAA}} / W_{\mathrm{TAA}}$ values for $C$. molitorella from Songtao Reservoir, Xijiang River and the aquaculture pond were $39.34,40.81$ and 41.34 , respectively and the $W_{\text {EAA }} / W_{\text {NEAA }}$ values were 78.27, 85.03 and 87.02 respectively. According to the $\mathrm{FAO} / \mathrm{WHO}$ criteria, high quality proteins have $W_{\text {EAA }} / W_{\text {TAA }}$ values of about $40 \%$ and $W_{\text {EAA }} / W_{\text {NEAA }}$ values over $60 \%$. The amino acid composition of $C$. molitorella from the three sampling sites met these requirements. Thus, $C$. molitorella from the three sampling sites showed well balanced amino acid composition.

The main FAAs found in fish are glutamic acid, aspartate, alanine and glycine. The content and composition of FAAs reflect the quality in terms of taste of animal 
flesh. The FAA content in C. molitorella from the three sampling sites increased in the order from the aquaculture pond, Xijiang River and Songtao Reservoir, with the content from Songtao Reservoir significantly higher than that from the aquaculture pond which indicated that C. molitorella from Songtao Reservoir tasted better than that from the aquaculture pond.

Protein is the most important nutritional component in food. Furthermore, amino acid content and appropriate composition is important for high quality food. The proportion of amino acids in fish, especially the EAA, will be consistent with their natural food organisms. In $C$. molitorella, glutamic acid content was highest, followed by aspartate, lysine and leucine; cystine was the lowest, with histidine, methionine and proline also relatively low. With respect to amino acid proportion, $S$. chuatsi wasverysimilarto C. molitorella, with themaximal difference lower than $0.7 \%$, indicating similar nutritional composition for the two species. Essential amino acids are the most important determinant of the nutritive value of prey fish. In the present study, we found that the total and single EAA proportions of C. molitorella were higher than those of $S$. chuatsi, except for arginine and threonine, which were $0.3 \%$ lower. These results indicate that C. molitorella met the nutritional requirements of $S$. chuatsi as a food source with respect to EAA. The nutritional physiology and environmental adaptation of predator species, such as $S$. chuatsi, are influencing factors with regard to food/prey choice (Liang et al., 1995). Our results showed that the EAA composition in C. molitorella satisfied the nutritional requirements of $S$. chuatsi and hence $C$. molitorella appears to be suitable as a high quality food organism for $S$. chuatsi.

In C. molitorella from all three sampling sites, the lysine score was higher than that of the other EAAs and methionine and cystine scores were relatively low. In general, no significant differences were observed in single amino acid scores among the $C$. molitorella samples from the three sampling sites (tryptophan excluded). These results indicate that $C$. molitorella had well-balanced amino acid composition and abundant lysine content. Furthermore, C. molitorella from Xijiang River had the highest EAAI value, followed by that from Songtao Reservoir and the aquaculture pond.

Amino acid content of $C$. molitorella was higher than that of C. idella, H. molitrix, A. nobilis, C. carpio, and $C$. auratus and lower than that of $S$. chuatsi. The average $W_{\text {EAA }} / W_{\text {TAA }}$ value of $C$. molitorella from the three sampling sites was slightly higher than that of the other seven fish species, while the average $W_{\text {EAA }} / W_{\text {NEAA }}$ value was significantly higher. This indicated that the amino acids in C. molitorella were well-balanced, but protein quality was poorer.

Results of the present study indicated that the flesh of $C$. molitorella had rich and well-balanced nutrients compared to certain other freshwater species. Results from the present study provide basic practical data for the development of aquaculture models to improve flesh quality of $C$. molitorella.

\section{Acknowledgements}

This project was partially funded by the Guangdong Provincial Oceanic Fisheries Special Technology Promotion Project (B201400B01) and the Special Scientific Research Funds for Central Non-Profit Institutes, South China Sea Fisheries Research Institute, Chinese Academy of Fishery Sciences (2014YJ01).

\section{References}

Cai, W. Q. 1980. Fisheries feed. Agriculture Publishing Company, Beijing, China, p. 114-115.

Chen, X. C. 1984. Applied human nutrition. People's Medical Publishing House, Beijing, China, p. 8-14.

Fu, Z. R., Bai, X. H., Zhao, S. H., Li, J., Liang, C. H. and Li, W. W. 2011. Quality and nutritive composition evaluation of three carp flesh. Hebei Fish, 6: 5-58.

Grigorakis, K. 2007. Compositional and organoleptic quality of farmed and wild gilthead seabream (Sparus aurata) and seabass (Dicentrarchus labrax) and factors affecting it: A review. Aquaculture, 272: 55-75.

GB5009.6-2003, 2003. Determination of fat in foods, National food safety standard. Ministry of Health of the People's Republic of China, Beijing, China, 6 pp.

GB/T5009.124-2003, 2003. Determination of amino acids in foods, National food safety standard. Ministry of Health of the People's Republic of China, Beijing, China, 6 pp.

GB5009.4-2010, 2010. Determination of ash in foods, National food safety standard. Ministry of Health of the People's Republic of China, Beijing, China, 6 pp.

GB5009.5-2010, 2010. Determination of protein in foods, National food safety standard. Ministry of Health of the People's Republic of China, Beijing, China, 6 pp.

Ge, C. Y. H. 2009. Main environmental problems and countermeasures of Songtao Reservoir in Hainan Province. J. Anhui. Agri. Sci., 37: 15948-15949.

Haard, N. F. 1992. Control of chemical composition and food quality attributes of cultured fish. Food Res. Int., 25: 289-307.

Li, Z. Z. 1988. The determination and comparison of essential amino acids in pollen, ganoderma and pearl. Amino Acids Biotic Resour., 4: 41-43. 
Liang, Y. Q., Liu, Y. L. and Cui, X. Q. 1995. The nutritional physiological analysis of $S$. chuatsi on the choice of forage fishes. Reserv. Fish., 1: 9-11.

Liu, J. K. 1990. Ecological study of East Lake. Science Press, Beijing, China, p. 307-311.

Liu, L., Yu, H. X. and Xiao, W. 2008. Research progress on fish quality. Inland Fish, 9: 9-12.

Nguyen, T. H. T., Van, N. S. and Thinh, D. V. 2013. Cirrhinus molitorella. The IUCN Red list of threatened species 2013: e.T166016A6168828. (Accessed 11 December 2015).

Solms, J. 1969. Taste of amino acids, peptides and proteins. J. Agr. Food Chem., 17: 686-688.
Tan, D. Q., Wang, J. W., Dan, S. G. and Li, W. J. 2004. The ratio of muscle to body and analysis of the biochemical composition of muscle in Megalobrama pellegrini. Acta Hydrobiol. Sin., 28(1): 17-22.

Yan, A. S., Xiong, C. X., Qian, J. W. and Wang, X. D. 1995. A study on the rate of flesh content of mandarin fish and nutritional quality of the flesh. J. Huazhong Agr. Univ., 14(1): 80-84.

Zhang, C. Y., Li, L., Li, C. P. and Ren, B. Z. 1988. Biochemistry, $2^{\text {nd }}$ edn. People's Medical Publishing House, Beijing, China, p. 305-561.

Zhou, W. W., Chen, W., Zheng, X. L. and Su, S. 2009. Physiological function and clinical application of taurine. Mod. Agr. Sci. Technol., 24: 303-309.

Date of Receipt ～: 12.01 .2016

Date of Acceptance : 09.01.2017 